\title{
Anne-Pascale Pouey-Mounou, Petite poésie portative: les exercices de style des «Epithetes» de La Porte
}

\section{Filippo Fonio}

\section{(2) OpenEdition}

1 Journals

\section{Edizione digitale}

URL: https://journals.openedition.org/studifrancesi/39127

DOI: 10.4000/studifrancesi.39127

ISSN: 2421-5856

\section{Editore}

Rosenberg \& Sellier

\section{Edizione cartacea}

Data di pubblicazione: 1 décembre 2004

Paginazione: $349-350$

ISSN: 0039-2944

\section{Notizia bibliografica digitale}

Filippo Fonio, «Anne-Pascale Pouey-Mounou, Petite poésie portative: les exercices de style des

«Epithetes» de La Porte», Studi Francesi [Online], 143 (XLVIII | II) | 2004, online dal 30 novembre 2015, consultato il 19 mai 2021. URL: http://journals.openedition.org/studifrancesi/39127 ; DOI: https:// doi.org/10.4000/studifrancesi.39127

Questo documento è stato generato automaticamente il 19 mai 2021.

\section{(c) $(1) \ominus$}

Studi Francesi è distribuita con Licenza Creative Commons Attribuzione - Non commerciale - Non opere derivate 4.0 Internazionale. 


\section{Anne-Pascale Pouey-Mounou, Petite poésie portative: les exercices de style des «Epithetes» de La Porte}

Filippo Fonio 


\section{NOTIZIA}

ANNE-PASCALE POUEY-MOUNOU, Petite poésie portative: les exercices de style des «Epithetes» de La Porte, “Bibliothèque d'Humanisme et Renaissance”, LXV, 1 (2003), pp. 51-67.

1 Si tratta del primo repertorio di epiteti in lingua francese (1571), sul modello di opere come quella di Ravisius Textor, e capostipite di una serie di altri repertori risalenti in particolare ai sec. XVI e XVII. La struttura è quella di un dizionario - pur con deroghe, rimandi non immediati e difficoltà di consultazione, come mostra l'autrice - nato dall'esperienza di un lettore e rivolto tanto a lettori ed esegeti di poesia, quanto a poeti e scrittori, per i quali il repertorio si presta nelle intenzioni a essere uno strumento di lavoro. La Porte assegna a Ronsard il primato nella creazione e nell'utilizzo di epiteti.

2 Il criterio su cui tanto la classificazione quanto il sistema dei riferimenti si basano è quello dell'aptum, del prepon, del decorum, come del resto sarà per i repertori successivi a quello di La Porte. Proprio per questo, "loin d'énoncer une simple définition ou une précision anecdotique, il indique à quoi sert une réalité donnée, assigne au référent une fonction dans l'univers au moment où la liste d'épithètes assigne à son substantif les épithètes appropriées. Le rapport qui s'établit entre les mots se fonde sur celui qui est censé régner entre les choses», p. 53. Lo studio della tecnica dell'espressione sconfina insomma in quello della tecnica dello sguardo.

3 L'opera, caratterizzata da anomalie e peculiarità tanto nei confronti del genere al quale appartiene, quanto al proprio interno, fra le singole entrate, avrebbe a parere dell'autrice carattere ludico più che pratico. 